\title{
Urological Manifestations of Placenta Percreta
}

\author{
Mina A. Ibrahim ${ }^{\mathrm{a}}$ Angela Liu ${ }^{\mathrm{a}} \quad$ Amanda Dalpiaz $^{\mathrm{a}}$ Richard Schwamb \\ Kelly Warren ${ }^{\mathrm{a}}$ Sardar A. Khan ${ }^{\mathrm{b}}$ \\ ${ }^{a}$ Department of Physiology and Biophysics; ${ }^{b}$ Department of Urology, SUNY School of Medicine, Stony Brook University, \\ Stony Brook, N.Y., USA
}

\section{Key Words}

Abnormal placentation • Pregnancy • Hematuria • Placenta • Post postpartum hemorrhage $\cdot$ Shock • Placenta percreta • Pregnancy

\begin{abstract}
Placenta percreta is a condition of pregnancy associated with abnormal decidua placenta. It is characterized by invasion of chorionic villi past the myometrium and serosa, towards urogenital organs. Complications include massive hemorrhage, bladder dysfunction, and severe infections during delivery. Reports suggest an increasing prevalence of this condition. From a urological perspective, this review suggests how early diagnostic modalities, effective treatment plans, and appropriate surgical methods may aid in decreasing the morbidity and mortality of placenta percreta. The importance of maintaining bladder integrity during hysterectomy is emphasized.

Copyright $\odot 2014$ S. Karger AG, Basel
\end{abstract}

\section{Introduction}

Adherent placenta disorders represent potentially fatal conditions for pregnant women. Branching villi of the placenta are important for nutrient exchange between mother and fetus. If villi from the fetal component (chorionic placenta) abnormally attach to the myometrium instead of the endometrium (decidua), pathologies known as placenta accreta, placenta increta, or placenta percreta can result [1]. This review focuses on placenta percreta, which is more severe than the other classifications. In placenta percreta, chorionic villi breach the uterine serosa and adhere to surrounding organs (bladder, ureters, or rectum).

Techniques for optimal management of placenta percreta remain controversial due to a lack of studies on treatment and long-term outcomes of this condition [2]. This review aims to synthesize available diagnostic and treatment methods for placenta percreta. It highlights the importance of early detection in avoiding complications, adoption of multidisciplinary surgical teams and patient counseling, and maintenance of the bladder during hysterectomy. Damage to the bladder results in sexual and urinary dysfunction, which can significantly reduce the patient's quality of life.

Anatomy, incidence, etiology, risk factors, clinical manifestations, early detection procedures, and different treatment options are discussed with a unique urological approach integrated into the traditional obstetrical approach to placenta percreta.

\section{KARGER}

Fax +4161306 1234

E-Mail karger@karger.ch

www.karger.com
(C) 2014 S. Karger AG, Basel

1015-9770/14/0082-0057\$38.00/0

Accessible online at:

www.karger.com/cur
Sardar A. Khan

Department of Urology, Stony Brook University HSC Level 9 Room 040, SUNY at Stony Brook

Stony Brook, NY 11794-8093 (USA)

E-Mail skysalik@gmail.com 


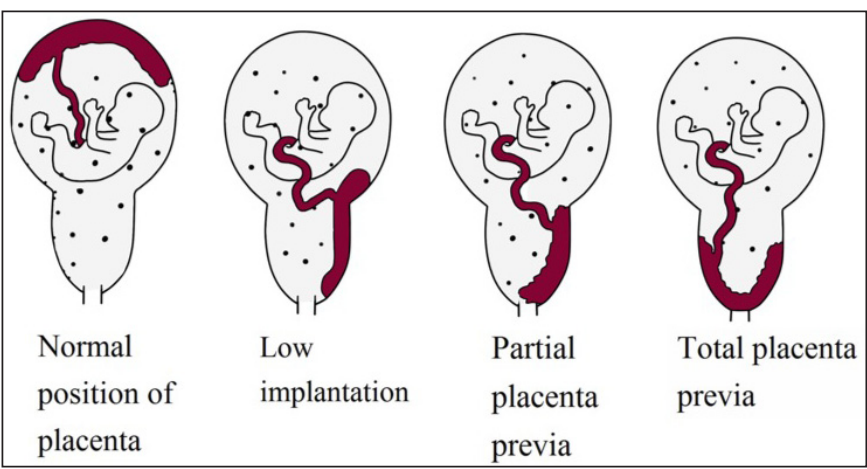

Fig. 1. Normal and abnormal placentation.

\section{Anatomy}

The anatomy of the uterus with respect to the bladder, ureter, and rectum provides a foundation for understanding the pathology of placenta percreta. The uterus lies posterior and superior to the bladder, and sits between the bladder and rectum $[3,4]$. Due to its close proximity to the ureter, the bladder may suffer damage during hysterectomies if the surgeon does not aim to preserve its function.

The uterus is peritonealized by the broad ligament and is comprised of 3 parts: the fundus, the body and the cervix [5]. The uterine wall is composed of 3 layers: the endometrium, myometrium and serosa (perimetrium). The endometrium has a functional layer and a basal layer. The functional layer consists of uterine arteries and veins that become basal straight arteries or spiral endometrial arteries [5]. High levels of estrogen and progesterone lead to development of more spiral arteries, causing the endometrium's functional layer to thicken. The basal layer does not change with increases in hormone production. It is the deepest layer of the endometrium and contains tube-like uterine glands [5]. Damage to the basal layer may cause intrauterine scars referred to as Ashermans syndrome, which allows placental adhesions to occur [6].

The myometrium contains the origin of spiral and straight arteries, which are branches from the arcuate artery. The arcuate artery originates from the uterine artery [7]. Both the uterine artery and arcuate artery are located within the myometrium [7].

The serosa (perimetrium) is the outermost layer of the uterus. The ureters collect urine and run anteriorly to the bifurcation of the common iliac artery and pass under the uterine vessels. As the fetus becomes larger, the positioning of the uterus will impact the bladder, leading to an

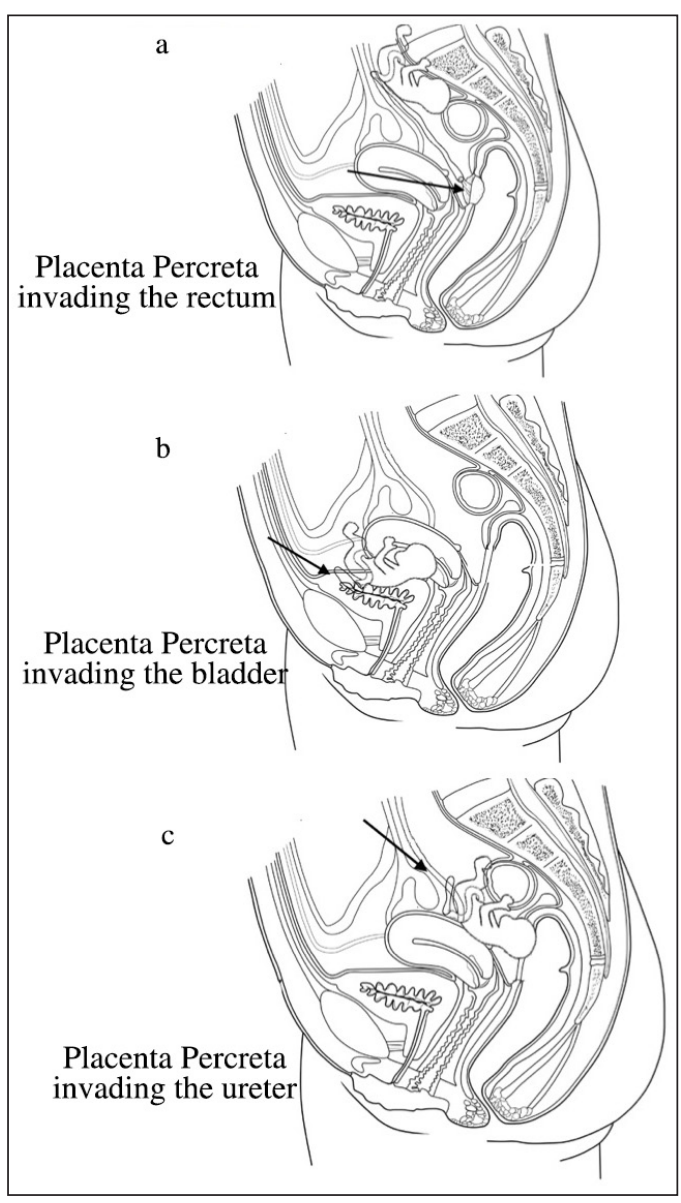

Fig. 2. Placenta percreta invading pelvic organs.

increase in voiding. Figures 1,2 , and 3 demonstrate the different positions that the infant may be inappropriately placed in.

The placenta develops after implantation [8]. During implantation, the cytotrophoblast gives rise to the syncytiotrophoblast. The syncytiotrophoblast invades the endometrium and develops into the fetal portion of the placenta [8]. By the end of the second week of gestation, fetal components of the placenta come into contact with maternal blood [8]. Fetal components form branching villi, which are surrounded by an intervillus space, allowing reception of maternal blood [8]. This is important for nutrient exchange between mother and fetus. If villi from the fetal component (chorionic placenta) abnormally attach to the myometrium instead of the endometrium (decidua), pathologies known as placenta accreta, or placenta increta or placenta percreta [1] can result. Disorders are shown in table 1 which relate to placenta disorder. 


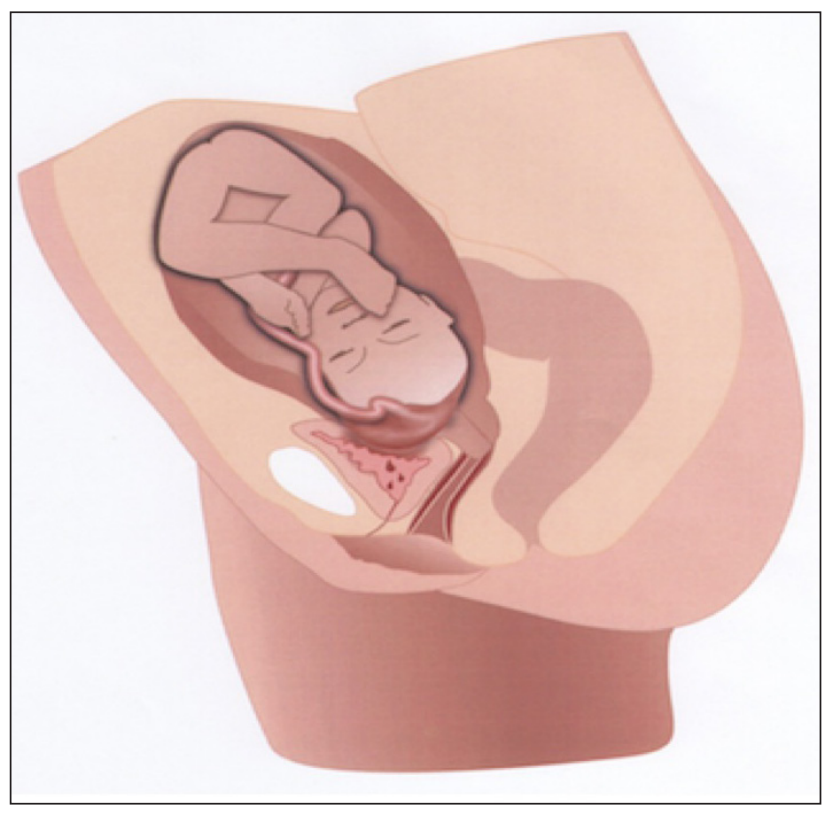

Fig. 3. Placenta invasion towards the bladder resulting in placenta percreta.

\section{Incidence}

There have been many reports on the incidence of placenta percreta. Although the literature suggests that there is an increase in the incidence of placenta percreta, the exact value is hard to determine. Reports assessed that in the 1950's United States, 1 in 30,000 deliveries were reported with placenta accreta, while in the 1990's 1 in 533 deliveries were reported with placenta accreta [9, 10]. In 138 histologically confirmed samples of adherent placentas, placenta accreta was the most commonly reported finding of all adherent placenta disorders representing $79 \%$ of all cases; meanwhile plancenta increta was estimated at $14 \%$ and placenta percreta was estimated at $7 \%[9,10]$. Pohl [11] estimates the incidence of placenta percreta as between 1:1000 to 1:70,000 births.

The incidence of placenta percreta still remains unclear, as it is a subset of adherent placenta pathologies. The exact incidence is difficult to determine as the invasiveness of the placenta is not always established, making it challenging to distinguish between placenta percreta, increta, and accreta.

Many institutions have conducted case control studies evaluating the incidence of placenta percreta within their healthcare networks. The following discusses the results of each study. In a 12-year study from 1986 to 1998 , there were 250 cases reporting adherent placen-

Urological Manifestations of Placenta Percreta
Table 1. Adherent placenta disorders

\begin{tabular}{llc}
\hline Classification & Presentation & Ref. \\
\hline Placenta accreta & $\begin{array}{l}\text { chorionic villi adheres to superficial } \\
\text { myometrium } \\
\text { chorionic villi adheres to body of } \\
\text { myometrium } \\
\text { Placenta increta }\end{array}$ & {$[1]$} \\
Placenta percreta & $\begin{array}{l}\text { adheres to surrounding organs (bladder, } \\
\text { ureters, or rectum) }\end{array}$ & {$[1]$} \\
& &
\end{tabular}

tas, $2(0.008 \%)$ of which were placenta percreta out of 25,254 births [12]. In Japan, within 8 tertiary centers, a 10 -year case control study was conducted from 1994 to 2004. Amongst the 59,008 reported deliveries, 5 were associated with placenta percreta [13]. These findings suggest that incidence of placenta percreta is uncertain at this time.

\section{Etiology}

Although the etiology of adherent placenta remains uncertain, the most widely accepted theory is that this pathology arises due to one or more of the following conditions: a defective decidua, maternal vascular remodeling, or excessive trophoblastic invasion [14]. Excessive trophoblastic growth may lead to uncontrolled invasion towards the myometrium resulting in placenta accreta, while dehiscence of a scar allows chorionic villi greater access to invade past the superficial myometrium resulting in placenta increta or placenta percreta [14]. These changes are thought to arise from operative procedures leading to the alteration of the deciduas basilis [15]. Eighty percent of adherent placenta disorders are most commonly found in Parity scores of greater than one, with a minimum of one pervious cesarean delivery [14]. Using a literature search, in 37 case studies reporting on placenta percreta, the maximum age was 43 , the minimum age was 24 , and the average age was 33 . The average number of cesarean deliveries amongst those cases was 2 .

\section{Diagnosis}

\section{Risk Factors}

There are various risk factors associated with placenta percreta. The most important risk factor is the observation of placenta previa (low lying placenta) after a cesar- 
ean delivery. Maternal age of 33 or greater, and multiple cesarean deliveries increase the risk for adherent placenta disorders, therefore a detailed past medical history is essential to determine the overall risk and to anticipate complicated placental implantation disorders $[10$, 16-18]. Other risk factors for placenta percreta include, submucous myoma, previous curettage, Asherman's syndrome, advanced maternal age, gandmultiparity, smoking, chronic hypertension as well as a pervious history with adherent placenta disorders $[18,19]$.

Placenta percreta being the most severe form of all implantation disorders requires aggressive evaluation and management to decrease patient morbidity [16]. Literature suggests that placenta percreta can be diagnosed as early as the 11th week of gestation, however the mode diagnosis of placenta percreta was observed at 35 weeks of gestation. This value illustrates a need for earlier diagnosis, as in the later stages of pregnancy a higher risk for painful obstetric hemorrhage exists [20]. Furthermore, an early diagnosis allows adequate preparation for delivery, thus optimizing patient safety and outcomes.

\section{Clinical Manifestations of Placenta Percreta}

Placenta percreta is a result of chorionic villi invading surrounding organs, such as the bladder, ureters, rectum [21]. Hematuria is a rare occurrence comprising $25 \%$ of all placenta percreta cases [1]. Multiparous women with a history of cesarean deliveries with placenta previa and hematuria should be suspected with placenta percreta [1]. Women who have any of the aforementioned risk factors should undergo a pelvic ultrasound with high suspicion for adherent placenta disorders [22]. If there are no incidental findings, placenta percreta should not be ruled out, as presentation in the ultrasound may be uncertain. Patients with placenta percreta may also complain of a dull, prolonged lower abdominal pain that is unusual during pregnancy [1]. Vaginal bleeding has been reported in presentation of placenta percreta [23]. If there are suspicions, development of a team-based delivery plan involving a blood bank team, obstetricians, interventional radiologists, anesthesiologists, vascular surgeons, neonatologist and urologists will help reduce the risk of massive hemorrhaging, and other complications during delivery [22]. The benefits of a multidisciplinary team will be discussed in detail later in this review.

\section{Morbidity and Mortality of Placenta Percreta}

Placenta percreta is a highly morbid condition as it can result in massive hemorrhaging causing maternal and prenatal death. Urological complications of placenta per- creta include ureteral dilation [23] and fistula between the bladder and cervix [24]. Most cases of placenta percreta are diagnosed only at the time of delivery, requiring aggressive treatment $[25,26]$. This requires the need for extensive surgery that may result in massive blood transfusions, urological injury and infections [25]. A recent study measuring women with morbidly adherent placenta disorders recorded that out of 20 case records with incidence of bleeding complications, the average blood loss was 2.71 units, with a high of 19 units [25]. Takai et al. [27] reports an extreme placenta percreta case in which the patient lost $11,130 \mathrm{ml}$ of blood, requiring 59 units to be transfused. Hemorrhaging can prove fatal as it may cause hemorrhagic shock and coagulopathy. Due to the large volume of blood loss it is important for clinicians be prepared to supply adequate amount of blood volume during delivery [28], in addition to identifying patients who may be at risk for placenta previa. As discussed earlier, certain risk factors including placenta previa and several cesarean sections should alert clinicians to screen for this condition. Next section will explain diagnostic procedures currently available to screen for placenta percreta.

\section{Radiological Findings and Imaging Techniques}

Ideal diagnosis of adherent placenta disorders should be done during the antenatal stage [29]. Grayscale ultrasound exam is an imaging technique that can display critical features during the first trimester including, low-lying gestational sacs attached to a uterine scar. The myometrium was observed as being thin in the area of the scar [30]. During second and third trimester, ultrasound may reveal multiple placental lakes ("Swiss cheese" appearance adjacent to the placenta), a thin myometrium, loss of decidua placental layer, and an irregular border between the bladder and myometrium $[1,31]$. Three-dimensional color flow Doppler can help support grayscale ultrasonography by helping detect angioarchitecture of the basal and lateral views of the placenta, helping assess the placenta condition [32, 33].

If greyscale ultrasound provides inconclusive results, a magnetic resonance imaging (MRI) technique should be performed using gadolinium contrast intravenously [19]. An MRI may reveal absence of the inner layer of the myometrium, the mass effect of the placenta extending beyond normal zones or into the underlying bladder, and beading nodularity within the placenta $[30,34]$. Cystoscopy may be used to display the condition of the posterior bladder wall and reveal associated abnormalities [27]. 
Table 2. Placenta percreta diagnostic methods for early detection

\begin{tabular}{ll}
\hline Technique & Features of clinical significance \\
\hline Grayscale ultrasound & $\begin{array}{l}\text { low-lying gestational sacs attached to a uterine scar during } 1^{\text {st }} \text { trimester } \\
\text { multiple placental lakes, a thin myometrium, loss of decidua placental layer, and an irregular border } \\
\text { between the bladder and myometrium during } 2^{\text {nd }} \text { and } 3^{\text {rd }} \text { trimester } \\
\text { help support a gray-scale ultrasonography via detection of angioarchitecture of the placenta and the } \\
\text { myometrium } \\
\text { Color doppler } \\
\text { MRI w/gadolinium contrast } \\
\text { derlying bladder or if it extends beyond the normal zones, and beading nodularity within the placenta } \\
\text { reveals the condition of the posterior wall of the bladder and if abnormalities are present }\end{array}$ \\
\hline
\end{tabular}

Table 3. Multidisciplinary team and treatment modalities

\begin{tabular}{|c|c|c|c|c|}
\hline Specialty & Pre-operative & Intra-operative & Post-operative & Ref. \\
\hline Obstetrician & $\begin{array}{l}\text { patient counseling } \\
\text { physical exam } \\
\text { early diagnosis with different imaging } \\
\text { modalities }\end{array}$ & $\begin{array}{l}\text { laparoscopic Cesarean hysterectomy } \\
\text { emergency hysterectomy }\end{array}$ & $\begin{array}{l}\text { methotrexate therapy } \\
\text { postpartum hysterectomy } \\
\text { postoperative follow-up }\end{array}$ & $\begin{array}{l}{[1,29,30,32} \\
33,36,39-41]\end{array}$ \\
\hline $\begin{array}{l}\text { Interventional radiolo- } \\
\text { gist }\end{array}$ & & $\begin{array}{l}\text { angiography guided balloon occlusion } \\
\text { of uterine arteries } \\
\text { prophylactic internal iliac embolization } \\
\text { bilateral internal iliac artery catheters }\end{array}$ & postoperative follow-up & {$[19,37,41]$} \\
\hline Neonatologist & & $\begin{array}{l}\text { assess the condition the newborn } \\
\text { neonatal resuscitation if needed }\end{array}$ & & {$[19,37,41]$} \\
\hline Anesthesiologist & & $\begin{array}{l}\text { general anesthesia } \\
\text { spinal anesthesia } \\
\text { epidural anesthesia }\end{array}$ & & {$[19,37]$} \\
\hline Urologist & assess gestational hematuria if present & $\begin{array}{l}\text { ureter stent placement } \\
\text { partial bladder resection } \\
\text { bladder cystotomy } \\
\text { bilateral ureteral catheters } \\
\text { bladder reconstruction }\end{array}$ & post surgical follow-up & {$[1,19,36,41]$} \\
\hline Blood bank physician & $\begin{array}{l}\text { blood typing and Rh screening } \\
\text { cross and check blood products } \\
8 \text { units of packed red blood cells and } \\
4 \text { units of fresh frozen plasma are rec- } \\
\text { ommended }\end{array}$ & $\begin{array}{l}\text { provide adequate blood for blood trans- } \\
\text { fusion } \\
\text { have rapid infusion device on hand }\end{array}$ & & {$[25,41]$} \\
\hline
\end{tabular}

CT scans and X-rays are not recommended because they expose the fetus to unnecessary radiation. Although these methods may provide insight on the possible presence of adherent placenta disorders, there is no early definitive diagnostic method that exists for clinicians. Diagnosis is often made via postpartum hemorrhage [19]. However, early detection allows for clinicians to formulate an interventional plan and adequate perpetration if placenta percreta were to occur. Some early detection techniques are outlined in table 2.

Urological Manifestations of Placenta Percreta

\section{Patient Counseling and the Multidisciplinary Team Approach}

For patients at high risk or with suspected diagnosis for adherent placenta disorders, patient counseling and interventional surgical plans should be discussed. During the counseling session, the patient should be made aware of the increased risk of maternal death, likelihood for a hysterectomy, need for blood transfusion, and risk associated with removing parts of the bladder or invaded ureters [35]. Reports indicate that there is a greater ben- 
efit and decrease in mortality for planned hysterectomy versus an emergent peripartum hysterectomy $[19,36]$.

In addition to counseling, a multidisciplinary team should be constructed. A team comprising an obstetrician experienced in pelvic surgery, a blood bank team, an anesthesiologist, a urologist skilled in pelvic reconstruction, an interventional radiologist, and an experienced neonatologist is advised [19, 37]. Table 3 signifies the roles of each specialty in the treatment plan. Eller et al. [37] report significant reduction in morbidity and mortality with utilization of a multidisciplinary team. This signifies the importance of patient counseling and the development of a multidisciplinary team towards successive treatment of placenta percreta.

In summary, an individualized care plan should be tailored to the patient's wishes, risk factors, and invasion extent and positioning of placenta [38].

\section{Treatment}

\section{Treatment Options}

Currently there are two main therapeutic options for treatment of placenta percreta: cesarean hysterectomy and the conservative approach. The extirpative approach is another method that is seldom administered with placenta percreta $[42,43]$. The conservative approach does not remove the placenta with an aim towards preventing further hemorrhaging [19]. The placenta is left in situ post-delivery and adjunct therapy is administered such as methotrexate, angiography guided balloon occlusion, uterine artery embolization, internal iliac artery ligation/ embolization, dilatation and curettage, and/or hysteroscopic loop resection $[42,44]$. The extirpative approach removes the placenta, leaving the uterine cavity empty at the time of delivery and is theorized to elevate the risk of postpartum hemorrhage [42, 43]. Adopting a urological perspective to this obstetrical condition, we emphasize the importance of maintaining the integrity of a bladder if a hysterectomy is performed.

\section{Endovascular Treatment}

Literature suggests that angiography guided balloon occlusion and embolizations are the most effective conservative therapeutic methods for placenta percreta. The purpose of these 2 methods is to control hemorrhaging during or after cesarean delivery $[45,46]$. The process of balloon occlusion involves insertion of balloon catheters prior to delivery in each of the femoral arteries up toward the internal iliac arteries $[45,47]$. Once the balloons are placed, they can be inflated causing temporary occlusion of the internal iliac arteries followed by a cesarean section reducing blood loss and preventing massive hemorrhaging $[44,47]$. Prophylactic internal iliac embolization assisting cesarean delivery can be used intraoperatively to prevent intraoperative hemorrhage or it can be used post delivery to eliminate the need of reopening and closing the abdomen as the patient is transported between departments $[2,48]$. This process can be utilized after a balloon occlusion has been performed. Although these treatments are arguably the most favored conservative method approaches, opinions on their efficiency is mixed [44]. The literature suggests that outcomes with balloon occlusion alone have reduced risk than when assisted by arterial embolization [49]. Repeat embolizations of uterine arteries show that when used, they potentially increase the risk of developing bladder ischemia, sepsis, and pelvic abscesses [50]. In cases where reduced blood loss does not occur or hemorrhaging occurs, alternative therapies need to be in place to limit complications.

\section{Methotrexate: A Controversial Therapy}

Methotrexate is a drug therapy that aids in the detachment of the placenta when left in situ. Methotrexate is a chemotherapeutic and immunosuppression agent that acts via inhibition of DNA synthesis of rapidly dividing cells such as trophoblasts $[39,51]$. DNA synthesis inhibition affects the rapid replication of choronic villi resolving adherence of the placenta [39]. The use of methotrexate for the treatment of placenta percreta has been questioned, as outcomes of its use are unclear. Two reports illustrate that when the placenta is left in situ with controlled bleeding, methotrexate had positive therapeutic outcomes [52]. Conversely, two other reports have suggested that when methotrexate has been used as a conjunction therapy, serious morbidities occurred [53, 54]. The administration of methotrexate as a therapeutic aid for placenta percreta should be utilized with caution, as the therapeutic benefit has not been fully determined and it may lead to complications such as delayed bleeding, placing the patient at risk for hemorrhaging at a later period $[1,52]$. For pregnant patients unable or unwilling to undergo blood transfusion for excessive intraoperative blood loss acute normovolemic hemodilution is a viable treatment option [55].

\section{Hysterectomy}

Hysterectomy is the most common therapeutic method applied in conjunction with or without the conservative method. Most case reports that applied the conservative method have detailed that a postpartum hysterectomy 
was performed [43]. With placenta percreta cases, using laparoscopic hysterectomy over laparotomy is recommended as it improves visualization allowing for more dissection precision decreasing the risk of hemorrhage [43].

If diagnosis of placenta percreta is not determined or if conservative method is not applied, an emergency hysterectomy is often performed. An emergency hysterectomy presents a significant challenge, as there is greater risk for hemorrhage [56]. Matsubara et al. [36] report standard surgical methodologies for decreasing challenges associated with emergency hysterectomy. Ureter stent placement requires approximately 5 minutes for an experienced urologist and helps in assisting the obstetrician during the hysterectomy procedure [36].

Most placenta percreta cases report the presence of bladder wall invasion. It is important to note that even in a situation in which uterine bleeding is uncontrolled, every attempt to preserve bladder integrity should be made [1]. If the placenta invades the bladder wall, then opening the bladder for a cesarean hysterectomy is recommended [57]. The bladder should not be separated as it can cause severe blood loss. Because the bladder is a neurogenic organ, all efforts should be made to preserve its integrity. Potential long-term consequences of bladder damage include incontinence and sexual dysfunction. The posterior bladder wall, i.e. the trigone, the detrusor muscle and the ureter orifices, should remain intact. It is highly recommended that a urologist specializing in pelvic reconstruction be present during hysteroectomy [1]. If the bladder is partially resected, it should be done with an automatic stapling/cutting tool to maintain the structural components of the bladder $[1,36]$. The surgeon must use discretion in times of severe blood loss accounting for the appropriate steps for the preservation of the bladder. Bladder cystotomy is recommended as it can detail the extent of the invading placenta and aid the surgeon in defining dissecting patterns recommended for optimal therapeutic benefit [1].

\section{Conclusion}

Defects of decidua lead to proliferation of chorionic villi. Placenta percreta is a morbid condition that involves infiltration of choronic villi of the placenta past the myometrium of the uterus towards urogenital organs. The uterus lies posterior and superior to the bladder [5]. Thus, particular care must be taken to prevent bladder damage in case of hysterectomy.

Urological Manifestations of Placenta Percreta
Although exact values of placenta percreta incidence are unknown, it is believed that incidence of placenta percreta is increasing due to an increased number of cesarean deliveries. Placenta percreta is reported as having the lowest incidence of all placenta adherent disorders, though it may be most severe.

Obstetricians as well as urologists need to be aware of risk factors and clinical manifestations of placenta percreta. Placenta previa with pervious cesarean deliveries increases the likelihood of adherent placenta disorders. Clinicians should recognize that hematuria is not a definitive clinical manifestation of placenta percreta. Other indications for the possibility of placenta percreta include complaints of a dull lower abdominal pain.

Placenta percreta requires early diagnosis and treatment. Effective planning for severe blood loss needs to be considered. Imaging modalities such as grayscale ultrasound, color Doppler, an MRI with gadolinium contrast and cystoscopy, have all shown to be effective tools in the early detection of this condition.

Patient counseling and multidisciplinary team involvement have shown strong successive treatment for placenta percreta. Early planning can ensure optimal outcomes for the patient. Patient counseling allows for patient autonomy in making decisions such as possible termination of the pregnancy, early delivery via cesarean section, or planned hysterectomy.

The main treatment options include the conservative surgical approach, which leaves the placenta in situ during a cesarean delivery or a cesarean hysterectomy during delivery. The conservative approach often utilizes endovascular treatments such as balloon occlusion and/ or embolization to isolate the placenta during a cesarean delivery. The placenta is removed later, either via methotrexate or surgical innervation. A hysterectomy is the most common form of treatment for placenta percreta and can be performed during the cesarean delivery or after a cesarean has been performed using the conventional approach. Emergency hysterectomies have higher mortality outcomes than planned hysterectomies, further illustrating the need for early diagnosis and patient counseling. If a hysterectomy is performed with a patient with placenta percreta all efforts towards maintaining the integrity of the bladder should be made.

Curr Urol 2014;8:57-65 


\section{References}

1 Konijeti R, Rajfer J, Askari A: Placenta percreta and the urologist. Rev Urol 2009;11: 173-176.

2 Clausen C, Lonn L, Langhoff-Roos J: Management of placenta percreta: a review of published cases. Acta Obstet Gynecol Scand 2014;93:138-143.

- 3 Fritsch H, Lienemann A, Brenner E, Ludwikowski B: Clinical anatomy of the pelvic floor. Adv Anat Embryol Cell Biol 2004;175:1-64.

-4 Baader B, Baader SL, Herrmann M, Stenzl A: Autonomic innervation of the female pelvis. Anatomic basis. Urologe A 2004;43:133140.

5 Jarcho J: Malformations of the uterus; review of the subject, including embryology, comparative anatomy, diagnosis and report of cases. Am J Surg 1946;71:106-166.

6 Dmowski WP, Greenblatt RB: Asherman's syndrome and risk of placenta accreta. Obstet Gynecol 1969;34:288-299.

7 Khong TY, Robertson WB: Placenta creta and placenta praevia creta. Placenta 1987;8:399409.

8 Naish J, Court DS, Revest P: Medical Sciences. Vol 1, Elsevier, 2009.

-9 Wu S, Kocherginsky M, Hibbard JU: Abnormal placentation: twenty-year analysis. Am J Obstet Gynecol 2005;192:1458-1461.

10 Miller DA, Chollet JA, Goodwin TM: Clinical risk factors for placenta previa-placenta accreta. Am J Obstet Gynecol 1997;177:210 214.

11 Pohl R: The special case: rare gynecologic emergency of uterine perforation in placenta percreta. Fortschr Med 1979;97:2143-2144.

-12 Abbas F, Talati J, Wasti S, Akram S, Ghaffar S, Qureshi R: Placenta percreta with bladder invasion as a cause of life threatening hemorrhage. J Urol 2000;164:1270-1274.

-13 Sumigama S, Itakura A, Ota T, Okada M, Kotani T, Hayakawa H, Yoshida K, Ishikawa K, Hayashi K, Kurauchi O, Yamada S, Nakamura H, Matsusawa K, Sakakibara K, Ito M, Kawai M, Kikkawa F: Placenta previa increta/percreta in Japan: a retrospective study of ultrasound findings, management and clinical course. J Obstet Gynaecol Res 2007;33: 606-611.

14 Tantbirojn P, Crum CP, Parast MM: Pathophysiology of placenta creta: the role of decidua and extravillous trophoblast. Placenta 2008;29:639-645.

15 Bencaiova G, Burkhardt T, Beinder E: Abnormal placental invasion experience at 1 center. J Reprod Med 2007;52:709-714.

16 Gupta N, Gupta A, Green M, Kang HS, Blankstein J: Placenta percreta at 17 weeks with consecutive hysterectomy: a case report and review of the literature. Case Rep Obstet Gynecol 2012;2012:734834.

17 Clark SL, Koonings PP, Phelan JP: Placenta previa/accreta and prior cesarean section. Obstet Gynecol 1985;66:89-92.
Silver RM, Landon MB, Rouse DJ, Leveno KJ, Spong CY, Thom EA, Moawad AH, Caritis SN, Harper M, Wapner RJ, Sorokin Y, Miodovnik M, Carpenter M, Peaceman AM, O'Sullivan MJ, Sibai B, Langer O, Thorp JM, Ramin SM, Mercer BM: Maternal morbidity associated with multiple repeat cesarean deliveries. Obstet Gynecol 2006;107:12261232.

19 Garmi G, Salim R: Epidemiology, etiology, diagnosis, and management of placenta accreta. Obstet Gynecol Int 2012;2012:873929.

20 Bennett MJ, Sen RC: 'Conservative' management of placenta praevia percreta: report of two cases and discussion of current management options. Aust N Z J Obstet Gynaecol 2003;43:249-251.

-21 Ortiz-Villalobos RC, Luna-Covarrubias EE, Serrano-Enríquez RF, Laureano-Eugenio J, Mejía-Mendoza ML, Rodríguez-Rodríguez JG: Placenta percreta with invasion of the bladder, ureter and abdominal wall. Case report. Ginecol Obstet Mex 2013;81:487-493.

22 Thia EW, Lee SL, Tan HK, Tan LK: Ultrasonographical features of morbidly-adherent placentas. Singapore Med J 2007;48:799802.

23 Caliskan E, Tan O, Kurtaran V, Dilbaz B, Haberal A: Placenta previa percreta with urinary bladder and ureter invasion. Arch Gynecol Obstet 2003;268:343-344.

24 Roux D, Horovitz J, Pariente JL, Lajus C, Le Guillou M, Dubecq JP: Placenta praevia percreta with bladder invasion: a case report. J Gynecol Obstet Biol Reprod (Paris) 1992;21: 579-580.

25 Aggarwal R, Suneja A, Vaid NB, Yadav P, Sharma A, Mishra K: Morbidly adherent placenta: a critical review. J Obstet Gynaecol India 2012;62:57-61.

26 Wang PH, Chao HT, Yuan CC, Linn JJ, Yen MS: Placenta previa accreta with cervical involvement causing tenacious postpartum hemorrhage: a case report. Zhonghua Yi Xue Za Zhi (Taipei) 1998;61:116-120.

-27 Takai N, Eto M, Sato F, Mimata H, Miyakawa I: Placenta percreta invading the urinary bladder. Arch Gynecol Obstet 2005;271:274-275.

28 Sasaoka N, Kitamura S, Kinouchi K, Fukumitsu K, Taniguchi A, Tachibana K: Cesarean section in a pregnant patient with placenta percreta involving the urinary bladder. Masui 2000;49:755-758

29 Alkazaleh F, Geary M, Kingdom J, Kachura JR, Windrim R: Elective non-removal of the placenta and prophylactic uterine artery embolization postpartum as a diagnostic imaging approach for the management of placenta percreta: a case report. J Obstet Gynaecol Can 2004;26:743-746.

30 Comstock CH: Antenatal diagnosis of placenta accreta: a review. Ultrasound Obstet Gynecol 2005;26:89-96.
Yang JI, et al: Sonographic findings of placental lacunae and the prediction of adherent placenta in women with placenta previa totalis and prior Cesarean section. Ultrasound Obstet Gynecol 2006;28:178-182.

32 Shih JC, Lim YK, Kim HS, Chang KH, Lee JP, Ryu HS: Role of three-dimensional power Doppler in the antenatal diagnosis of placenta accreta: comparison with gray-scale and color Doppler techniques. Ultrasound Obstet Gynecol 2009;33:193-203.

- 33 Wong HS, Cheung YK, Zuccollo J, Tait J, Pringle KC: Evaluation of sonographic diagnostic criteria for placenta accreta. J Clin Ultrasound 2008;36:551-559.

34 Levine D, Hulka CA, Ludmir J, Li W, Edelman RR: Placenta accreta: evaluation with color Doppler US, power Doppler US, and MR imaging. Radiology 1997;205:773-776.

35 James DK, Steer PJ, Weiner CP, Gonik B: High Risk Pregnancy: management Options, ed 4. Elsevier, 2011.

- 36 Matsubara S, Kuwata T, Usui R, Watanabe T, Izumi A, Ohkuchi A, Suzuki M, Nakata M: Important surgical measures and techniques at cesarean hysterectomy for placenta previa accreta. Acta Obstet Gynecol Scand 2013:92: 372-377.

37 Eller AG, Bennett MA, Sharshiner M, Masheter C, Soisson AP, Dodson M, Silver RM: Maternal morbidity in cases of placenta accreta managed by a multidisciplinary care team compared with standard obstetric care. Obstet Gynecol 2011;117:331-337.

38 Wortman AC, Alexander JM: Placenta accreta, increta, and percreta. Obstet Gynecol Clin North Am 2013;40:137-154.

39 Cole MD: Using methotrexate to treat placenta accreta. AWHONN Lifelines 2002;6: 486-487.

40 Damiani GR, Landi S, Pellegrino A, Loverro G, Farina A, Cormio G: Caesarean scar pregnancy complicated by placenta percreta followed by suppurative appendicitis after conservative management with methotrexate. J Obstet Gynaecol 2014;34:545-546.

41 Russo M, Krenz EI, Hart SR, Kirsch D: Multidisciplinary approach to the management of placenta accreta. Ochsner J 2011;11:84-88.

42 Kayem G, Davy C, Goffinet F, Thomas C, Clément D, Cabrol D: Conservative versus extirpative management in cases of placenta accreta. Obstet Gynecol 2004;104:531-536.

43 Skinner BD, Golichowski AM, Raff GJ: Laparoscopic-assisted vaginal hysterectomy in a patient with placenta percreta. JSLS 2012;16: 143-147.

44 Knuttinen MG, Jani A, Gaba RC, Bui JT, Carrillo TC: Balloon occlusion of the hypogastric arteries in the management of placenta accreta: a case report and review of the literature. Semin Intervent Radiol 2012;29: 161-168. 
45 Dubois J, Garel L, Grignon A, Lemay M, Leduc L: Placenta percreta: balloon occlusion and embolization of the internal iliac arteries to reduce intraoperative blood losses. Am J Obstet Gynecol 1997;176:723-726.

46 Kidney DD, Nguyen AM, Ahdoot D, Bickmore D, Deutsch LS, Majors C: Prophylactic perioperative hypogastric artery balloon occlusion in abnormal placentation. AJR Am J Roentgenol 2001;176:1521-1524.

-47 Bodner LJ, Nosher JL, Gribbin C, Siegel RL, Beale S, Scorza W: Balloon-assisted occlusion of the internal iliac arteries in patients with placenta accreta/percreta. Cardiovasc Intervent Radiol 2006;29:354-361.

>48 Yi KW, Oh MJ, Seo TS, So KA, Paek YC, Kim HJ: Prophylactic hypogastric artery ballooning in a patient with complete placenta previa and increta. J Korean Med Sci 2010; 25:651-655.
49 Levine AB, Kuhlman K, Bonn J: Placenta accreta: comparison of cases managed with and without pelvic artery balloon catheters. J Matern Fetal Med 1999;8:173-176.

50 Chou MM, Hwang JI, Tseng JJ, Ho ES: Internal iliac artery embolization before hysterectomy for placenta accreta. J Vasc Interv Radiol 2003;14:1195-1199.

51 Steins Bisschop CN, Schaap TP, Vogelvang TE, Scholten PC: Invasive placentation and uterus preserving treatment modalities: a systematic review. Arch Gynecol Obstet 2011; 284:491-502.

52 Hays AM, Worley KC, Roberts SR: Conservative management of placenta percreta: experiences in two cases. Obstet Gynecol 2008; 112:425-426.

53 Butt K, Gagnon A, Delisle MF: Failure of methotrexate and internal iliac balloon catheterization to manage placenta percreta. $\mathrm{Ob}$ stet Gynecol 2002;99:981-982.
54 Jaffe R, DuBeshter B, Sherer DM, Thompson EA, Woods JR Jr: Failure of methotrexate treatment for term placenta percreta. Am J Obstet Gynecol 1994;171:558-559.

55 Estella NM, Berry DL, Baker BW, Wali AT, Belfort MA: Normovolemic hemodilution before cesarean hysterectomy for placenta percreta. Obstet Gynecol 1997;90:669-670.

56 Machado LS: Emergency peripartum hysterectomy: incidence, indications, risk factors and outcome. N Am J Med Sci 2011;3:358361 .

57 Matsubara S, Ohkuchi A, Yashi M, Izumi A, Ohwada M, Kuwata T, Usui R, Kuwata Y, Nakata M, Suzuki M: Opening the bladder for cesarean hysterectomy for placenta previa percreta with bladder invasion. J Obstet Gynaecol Res 2009;35:359-363. 